International Journal of Wireless \& Mobile Networks (IJWMN) Vol. 3, No. 1, February 2011

\title{
INTELLIGENT HUMIDITY SENSOR FOR - WIRELESS SENSOR NETWORK AGRICULTURAL APPLICATION
}

\author{
Kshitij Shinghal ${ }^{1}$, Dr. Arti Noor ${ }^{2}$, \\ Dr. Neelam Srivastava ${ }^{3}$, Dr. Raghuvir Singh ${ }^{4}$ \\ ${ }^{1}$ Department of E\&C Engg., Moradabad Institute of Technology, Moradabad, INDIA. \\ kshinghal@gmail. com \\ ${ }^{2}$ Department of M. Tech. VLSI Design Group, C-DAC, Noida, INDIA \\ artinoorecdacnoida.in \\ ${ }^{3}$ Department of E\&C Engg., Institute of Engineering \& Technology, Lucknow, INDIA. \\ neelamsrivastava2001@yahoo.com \\ ${ }^{4}$ Shobhit Institute of Engineering and Technology, Gangoh (SIET), INDIA. \\ r.singh@nicesociety.org
}

\begin{abstract}
Wireless Sensor Networks (WSN) is now widely used in precision agriculture applications. Sensors play an important role in WSN. The traditional humidity sensors employed in the agriculture have a drawback that they acquire a large amount of data which is to be transmitted or processed. Whereas the intelligent sensor proposed in this paper uses a conventional sensor and an embedded processor that can process the data acquired using algorithms to reduce the amount of data collected, to extract only relevant information and to present this information in a format which minimizes post-processing latency. As a result of which the final processing end has to perform a little computation that too only on features (like significant changes in humidity) rather on the huge data hence reducing the power consumption. The intelligent humidity sensor reduces the amount of data processed by $50 \%$ (depending upon humidity variations) and thereby also reducing the power consumption.
\end{abstract}

\section{KEYWORDS}

Humidity Sensor, Wireless Sensor Network (WSN).

\section{INTRODUCTION}

If we combine a sensor, an analog interface circuit, an analog to digital converter (ADC) and a bus interface in a single housing, we get an intelligent sensor. IEEE 1451.2 specification defines an intelligent sensor as a sensor that provides functions beyond those necessary for generating a correct representation of a sensed or controlled quantity [16]. This function typically simplifies the integration of the transducer into applications in a networked environment [1]. If we integrate all functions from sensor to bus interface in one chip, we get an integrated intelligent sensor. 


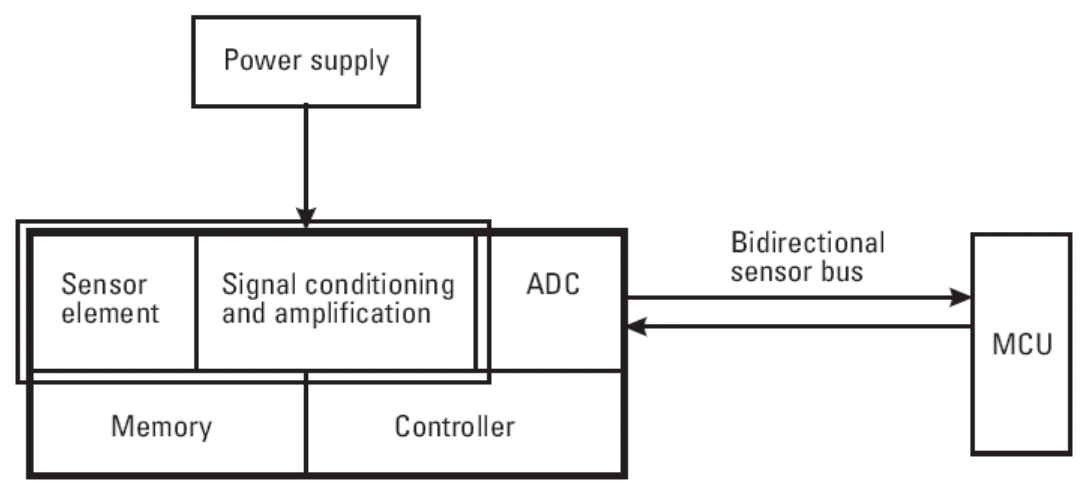

Figure 1 Intelligent sensor model [18]

An intelligent sensor has six main elements [2, 3, 4] as shown in Figure 1, in addition to the sensing element and its associated amplification and signal conditioning [23], an A/D converter, memory of some type, and logic (control) capability are included in the intelligent sensor [18, 26]. Once the signal is in digital format, it can be communicated by several communication protocols. Reducing the number of discrete elements in an intelligent sensor is desirable to reduce the number of components, form factor, interconnections, assembly cost, and frequently component cost as well [31].

Humidity sensors are used for determining the moisture content. Humidity or moisture is a universal parameter of common environments and its control is recognized to be very important in a variety of fields, such as industries related to precision manufacturing, fiber, food, and electronics industries [4]. Moisture is undesirable whether it appears in houses, textiles, packaging materials, electronic appliances, chemicals, dry foodstuffs, etc. Knowing the moisture content of materials is often very important. For example, soil moisture is fundamentally important to activities in agriculture, forestry, hydrology, and civil engineering. The moisture content of grains and like material has a significant impact on the market value of the grain. If grains have too high of moisture content they will sell for less than those in an appropriate moisture range [28]. Therefore, an accurate and precise means of testing moisture content in grain will help farmers monitor their crops. With the aid of monitoring, farmers may dry their grain until the preferred moisture content is achieved. Knowing the moisture content of soil would enable farmers to tailor their activities to achieve crop yield optimization. Soil moisture detection has been used for monitoring and evaluating construction sites, landscape sites, mining operations, forest areas, flood control areas, and farming districts. Moisture content measurements are important to sampling grain water content, field water content, and storage water content.

The most common problems that are involved with humidity sensors used in WSN node in agricultural applications is generation of large amount of data to be processed/transmitted, which consumes large amount of power from a small battery operated WSN node. Other associated problem is of corrosion of the connectors due to moisture, extreme/sudden temperature changes etc.

The rest of this paper is organized as follows: related work is given in Section 2, whereas Section 3 depicts the proposed intelligent humidity sensor design for WSN node along with proposed design block diagram, functions of different blocks, their specifications and implementations, while section 4 gives the simulation framework, section 5 summarizes results and finally section 6 concludes the paper. 
International Journal of Wireless \& Mobile Networks (IJWMN) Vol. 3, No. 1, February 2011

\section{RELATED WORKS}

The sensor node lifetime typically exhibits a strong dependency on battery life [21]. In many cases, the WSN node has a limited power source and replenishment of power may be limited or impossible altogether [30, 32]. Power consumption requires optimization.

In this paper, the approach is to optimize power in sensing unit by using intelligent sensor. This approach has been employed in the past in other areas like in smart homes, appliances in smart cars, in smart production machines, in biomedical applications [35] like hand vibration measurement [25], stress management [36], in recognizing the tool flank wear state over a range of cutting conditions [17], in robotics etc., but is not used in WSN nodes yet. This approach introduces new challenges (e.g. the interfacing problem, data processing issues, feature extraction, calibration etc.) and new opportunities to resolve such issues through intelligent sensor design.

More closely related to this work are the intelligent sensors being developed and used by NASA in space technology [16]. In the domain of sensor system, many commercial sensors are available for measuring humidity [20]. These are highly accurate, but rather bulky and expensive, not targeted for low power WSN node. The intelligent humidity sensor presented in this paper, serves a different purpose. The aim of this system is to combine the features of sensor with processor to reduce the post processing overhead, thereby reducing the overall power consumption [23, 33]. These efforts have made available inexpensive intelligent sensors that are equipped with sensing, data processing and wireless communication capabilities for wireless sensor network node [29]. Realizing the full potential of the intelligent sensors will require a new approach to identify intelligent sensor applications to create the next-generation products and systems [34].

\section{PROPOSED INTELLIGENT SENSOR DESIGN}

\subsection{Proposed design}

The intelligent humidity sensor is an indirect, calibrated method of measuring soil water. It is an electrical capacitance type sensor, the assembly along with casing of Intelligent Soil humidity sensor is shown in figure 2 which measures the electrical capacitance and transmits to an embedded processor.

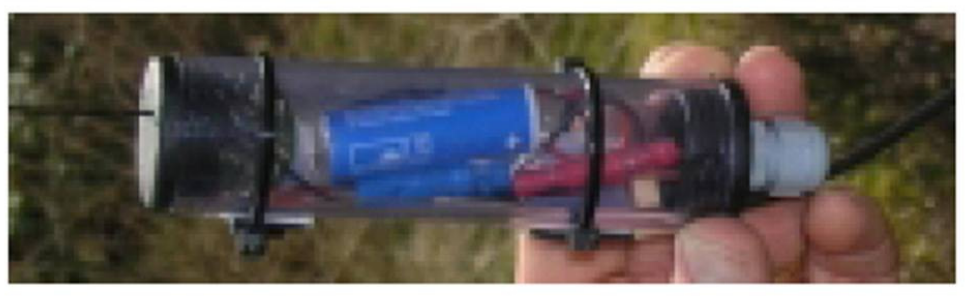

Figure 2 Humidity sensor with casing [10]

A calibration table is stored within sensor system memory whereby the pre-acquired different standard reference values of capacitances are stored in the memory map (calibration table) for processing by the intelligent humidity sensor embedded processor. That is, the humidity sensor uses the calibration table stored in the memory map of the embedded processor for displaying the calibrated reading of soil water tension. This intelligent humidity sensor can play a significant role in soil moisture measurement technology and hence can be very useful for the precision agriculture. The intelligent humidity sensor is an ideal solution for both agricultural and landscape applications. Its electrical characteristics make it ideally suited to use with a 
International Journal of Wireless \& Mobile Networks (IJWMN) Vol. 3, No. 1, February 2011

central master/base station electronic data processing equipment for collecting and processing data from various sensors deployed in agriculture field for precision agriculture applications [19].

The block diagram of an intelligent humidity sensor is shown in figure 3. An intelligent humidity sensor includes:

1. A sensing element that measures humidity.

2. A computational element that analyzes the measurements made by the sensing element,

3. A post processing interface to the outside world that allows the device to exchange information with other components in a larger system.

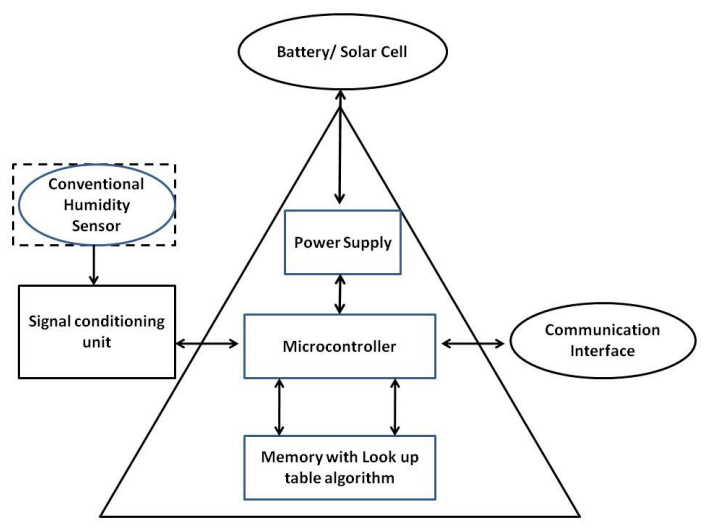

Figure 3 Block diagram of proposed intelligent sensor

It's the last two elements that really distinguish intelligent sensors from their more common standard sensor relatives because they provide the abilities to turn data directly into information, to use that information locally, and to communicate it to other elements in the system.

Intelligent humidity sensor will be having a corrosion proof enclosure, it will have fully solid state circuitry and the casing will neither dissolve in soil and nor it will react in contact with most soil, it will also Not affected by changing temperatures it will be having Internal compensation for commonly found salinity levels above all it will be Inexpensive so that it is affordable by the farmers and will have no technical hassles and will be easy to use so that it can be handled by non skilled persons and it will have very little or absolutely no maintenance. Intelligent humidity sensor can also be deployed in large numbers with Remote Sensing Unit transducers and RF communication transceivers for use with central master/base station electronic data processing equipment for WSNs.

\subsubsection{The Sensing Element}

A capacitance type humidity sensor is selected here as the sensing element in this intelligent sensor design. A capacitance type humidity sensor detects humidity by measuring the change in the electrostatic capacity of an element corresponding to the ambient humidity [11, 12]. Capacitive moisture meters deliver a capacitance value in dependence on the air humidity in the area around the measuring element. That capacitance value can be measured by means of an electronic evaluation system. A current moisture value is ascertained with the measured capacitance value, using further parameters such as temperature and comparative parameters $[13,14]$. Humidity sensing elements of the capacitance sensing type usually include a moistureinsensitive, non-conducting structure with appropriate electrode elements mounted or deposited on the structure along with a layer or coating of dielectric, highly moisture-sensitive material 
overlaying the electrodes and positioned so as to be capable of absorbing water from the surrounding atmosphere and reaching equilibrium in a short period of time. Capacitive moisture sensors are typically made by depositing several layers of material on a substrate material. The capacitance type humidity sensors typically do not exhibit a satisfactory linear relationship between the capacitance and humidity, and calibration is required to overcome this. For the calibration purpose reference data obtained from Honeywell $\mathrm{HCH} 1000$ series air humidity sensor was used [6].

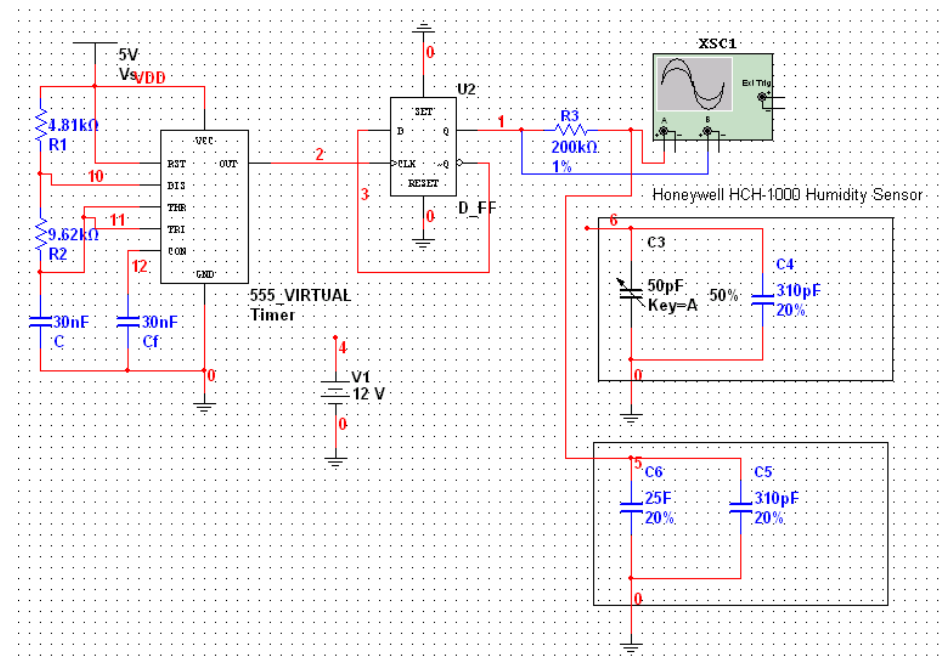

Figure 4 Circuit schematic of capacitive sensor

Capacitance is measured by applying $1 \mathrm{Vrms}$ at $20 \mathrm{kHz}$ at $25^{\circ} \mathrm{C}$. The sensor characteristic is determined by the following formula [6]:

$$
\mathrm{C}_{\mathrm{C}}(\% \mathrm{RH})=\mathrm{C}_{\mathrm{S}} \text { at } 55 \% \mathrm{RH}+\mathrm{S} \times\left[\left(\% \mathrm{RH}\left(\mathrm{C}_{\mathrm{M}}\right)-\% \mathrm{RH}\left(\mathrm{C}_{\mathrm{S}}\right)\right] \mathrm{pF}\right.
$$

Where $\mathrm{S}$ is Sensitivity $(\mathrm{pF} / \% \mathrm{RH}), \mathrm{CC}$ is $(\% \mathrm{RH})$ is calculated capacitance at the measured relative humidity, $\mathrm{CS}$ at $55 \% \mathrm{RH}$ is standard capacitance value at $55 \% \mathrm{RH}, \% \mathrm{RH}(\mathrm{CM})$ is measured relative humidity value, $\% \mathrm{RH}(\mathrm{CS})$ is standard relative humidity value $(55 \% \mathrm{RH})$.

$$
\% \mathrm{RH}\left(\mathrm{C}_{\mathrm{C}}\right)=\frac{\mathrm{C}_{\mathrm{M}}(\% \mathrm{RH})-\mathrm{C}_{\mathrm{S}} \text { at } 55 \% \mathrm{RH}}{\mathrm{S}}+\% \mathrm{RH}\left(\mathrm{C}_{\mathrm{S}}\right)
$$

The average increase in capacitance value within the working range of $10 \% \mathrm{RH}$ to $95 \% \mathrm{RH}$ is typically $56 \mathrm{pF}$.

Where $\mathrm{S}$ is Sensitivity $(\mathrm{pF} / \% \mathrm{RH}), \mathrm{CM}(\% \mathrm{RH})$ is Measured capacitance value, $\mathrm{CS}$ at $55 \% \mathrm{RH}$ is Standard capacitance value at $55 \% \mathrm{RH}, \% \mathrm{RH}(\mathrm{CC})$ Calculated relative humidity value at the measured capacitance, \% RH(CS) Standard relative humidity value (55\%RH).

\subsubsection{Computational Element}

Computational element used here is an application specific processor which can be later custom designed for the application. Here to perform the computational task a microcontroller 8051 is used. The microcontroller has several important tasks. First of all, it controls the sensor interface chip. It provides the settings of the sensor interface chip, such as the configuration of the readout electronics, the application mode and the duty cycle. Secondly, it gathers the data coming from the sensor interface chip and stores it in a memory. Furthermore, it performs the digital linearization and cross-sensitivity compensation. It use look-up tables, Look-up table 
algorithms offer good accuracy [7, 8, 9]. The microcontroller can also implement smart compression algorithms to extract the relevant data from the sensor signals. Hence, the amount of data that needs to be transmitted is decreased. This reduces the power consumption significantly, since the telemetry link has relatively large power consumption in the sensor node.

The microcontroller was programmed and incorporated in the circuit using co-simulation feature of NI Multisim -Multi MCU module [22]. A reference table was prepared and stored in the memory of the microcontroller. The microcontroller compared the acquired data with the reference look up table stored in the memory and processed/transmitted the data only when the acquired data from the sensor crossed the threshold points defined in the look up table. This concept can be further extended in such a way that a look up table can be prepared or updated dynamically by acquiring data from the sensor and can be compared with recently acquired data, processing will be done only if there is a significant change between the successive data.

\subsubsection{Post Processing Interface}

This is a post processing unit of the intelligent sensor. It could be readout, a wireless transceiver for the wireless sensor network node for communication with the master node or simply a storage device depending upon application of the intelligent sensor. In this paper two seven segment displays are used for displaying the humidity values but in actual wireless sensor network node application this will be replaced by a transceiver circuit for transmitting the information to neighboring node.

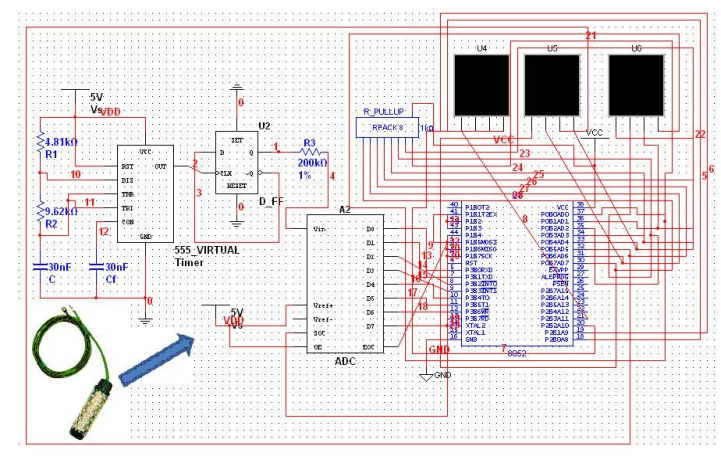

Figure 5 Circuit schematic of intelligent humidity sensor

\subsubsection{The Design of Housing}

The housing of intelligent humidity sensor should have following characteristics:

- The housing should be nonreactive with the moist soil.

- The housing must be tough and of unbreakable material.

- The housing design should have air openings that are as large as possible in the vicinity of the sensor.

- The sensor should not be mounted in the vicinity of heat sources. If it was, measured temperature would increase and measured humidity will decrease.

\subsection{Design Implementation}

The aim was to develop an intelligent humidity sensor which will not only reduce post processing latency but will also reduce the overall power consumption in a wireless sensor 
International Journal of Wireless \& Mobile Networks (IJWMN) Vol. 3, No. 1, February 2011

network node. This is achieved by reducing the amount of data transmitted by the post processing unit which shares a large amount of total power consumed by a WSN node there by resulting in a low power WSN node. First of all a capacitive humidity sensor was modeled using VHDL-AMS. The model was then used in Multisim in which 555 timer is configured to generate a square wave in astable mode. The output of astable multivibrator is given to a D flip flop, the output of which is fed to capacitive humidity sensor. Nominal Capacitance is $330 \mathrm{pF}$ at 25degree centigrade and Range is $+/-50 \mathrm{pF}$ across 5 to $95 \% \mathrm{RH}$, this is finally translated in to digital output using a ADC and then sent to microcontroller for post processing. Finally simulator is made run to perform run time verification.

\section{SIMULATION FRAMEWORK}

Before physically manufacturing an electronic circuit, an important stage is the simulation of its behavior in order to check its optimal functioning. Simulation processes require complex models for its components, models that can be achieved on basis of their behavior or on basis of state equations. SPICE is one of the most used simulators for analog circuits. In order to build models on basis of the equations it is possible to use VHDL-AMS, one of the languages that support the analog circuits description on basis of ordinary differential algebraic equations (ODAE) in order to complete the support needed to describe and simulate discrete events [27]. VHDL-AMS and its capability to provide communication between discrete events and continuous time systems, allows the creation of very complex models for the functioning of analog, digital and mixed signals electronic circuits. MULTISIM, manufactured by National Instruments, is a program conceived for the simulation of circuits that allow users to simulate circuit components, simultaneously with SPICE models and VHDL-AMS models [22]. The capacitive Sensor for humidity measurement presented in this paper, described in VHDL-AMS, is based on a SPICE model the validation of the model is being performed on basis of SPICE simulations, with use of MULTISIM program. First we will use MULTIVHDL program for writing and checking the VHDL code for the capacitive Sensor for humidity measurement. After validating this code we will create a new MULTISIM component, by using a link of this code. Hence, any modification of the VHDL code will be reflected in the functioning of the model used in the MULTISIM simulation.

\section{RESULTS AND DISCUSSION}

The calibration of air humidity unit was realized according to the reference data obtained for Honeywell HCH 1000 series air humidity sensor which works with an accuracy better than $1 \%$ [24]. The calibration was done using National instruments Multisim software and then was compared with a professional humidity measuring instrument. Figure $6,7 \& 8$ shows the graphs drawn on the basis of output data obtained by various simulation tests conducted using NI Multisim.

- There was nearly linear capacitance variation output interpreted from intelligent capacitive device based humidity sensor.

- This variation in capacitance was converted in to frequency and there was almost linear relationship between the output frequency and humidity.

- There is significant increase in performance of the sensor since it activates the post processing unit/communication unit only in the case of significant change in the humidity. 
International Journal of Wireless \& Mobile Networks (IJWMN) Vol. 3, No. 1, February 2011

Typical Capacitance as a function of humidity

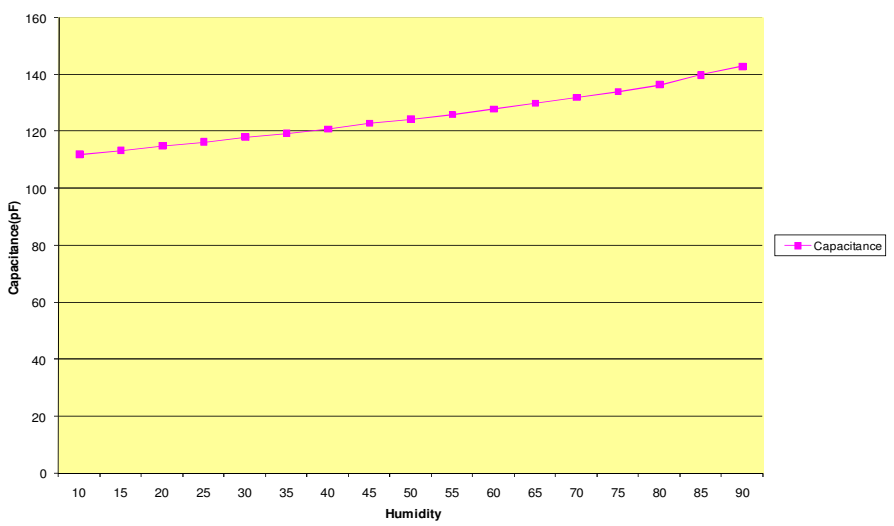

Figure 6 Typical Capacitance curve as a function of humidity

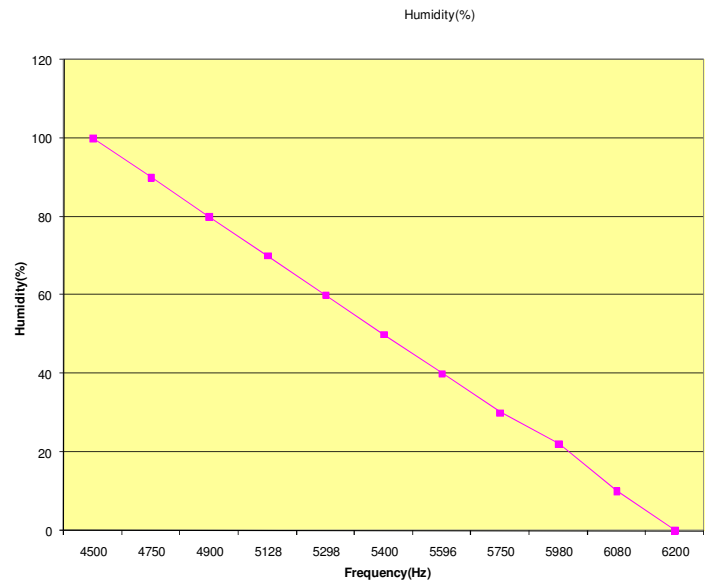

Figure 7 Simulation result for humidity with frequency

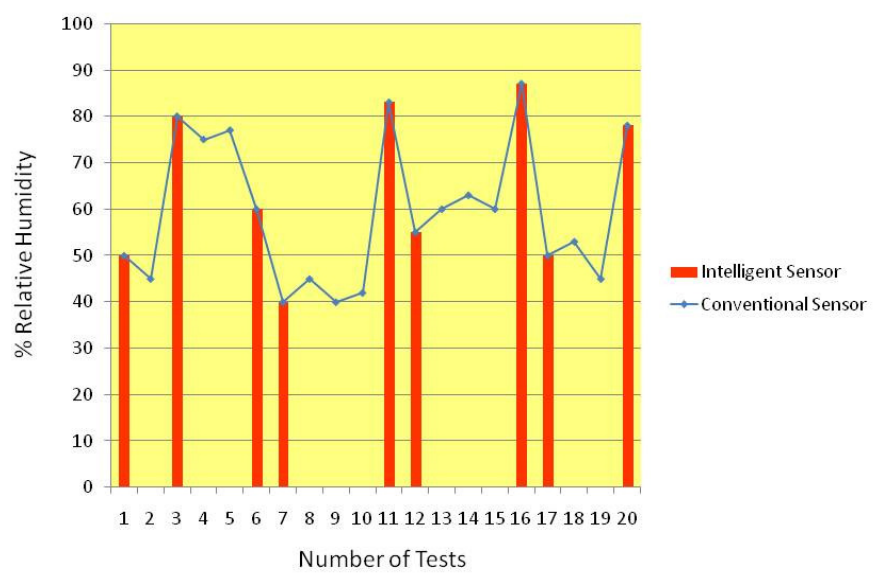

Figure 8 Comparison between conventional and intelligent sensor 
International Journal of Wireless \& Mobile Networks (IJWMN) Vol. 3, No. 1, February 2011

\section{CONCLUSIONS}

Intelligent humidity sensor can find a wide application in different areas, especially where it is needed to monitor and save bulk data for different agricultural and non-agricultural practices. The main sphere of using intelligent humidity sensor is at precision agriculture, automatic weather stations as well as at agro-meteorological and microclimatic stations. There are other uses: firstly as a model that is used for educational purposes at the lessons of the biometeorology and climatology and for developing routing algorithms for WSN; secondly in the industry and in other technological operations, where it is needed to monitor the humidity.

\section{REFERENCES}

[1] IEEE 1451.2 Standard, .A Smart Transducer Interface for Sensors and Actuators. Transducer to Microprocessor Communication Protocols and Transducer Electronic Data Sheet (TEDS) Formats,. Piscataway, NJ: IEEE Standards Department, 1998.

[2] Sensor Device Data/Handbook, DL200/D Rev. 4, 1998, Motorola Semiconductor Products Sector, Austin, TX.Najafi, K., .Smart Sensors,. J. Micromechanics and Microengineering, Vol. 1, 1991, pp. 86.102.

[3] Ina, O., .Recent Intelligent Sensor Technology in Japan,. Soc. Automotive Engineers, SAE891709, 1989.

[4] Maitan, J., .Overview of the Emerging Control and Communication Algorithms Suitable for Embedding Into Smart Sensors,. Proc. Sensors Expo, Cleveland, Sept. 20.22, 1994, pp. 485-500.

[5] E. J. Connoly , H. T. M. Pham , J. Groeneweg, P. M. Sarro and P. J. French "Relative humidity sensors using porous SiC membrane and Al electrodes," Sens. Actuators B, Chem., vol. 100, pp. 216, Jun. 2004.

[6] Installation Instructions for the $\mathrm{HCH}-1000$ Series Capacitive Humidity Sensors ISSUE 150018326.

[7] S. B. Crary, W. G. Baer, J. C. Cowles, and K. D. Wise, "Digital compensation of highperformance silicon pressure transducers", Sensors and Actuators A, 21-23:70-72, 1990.

[8] N. Yazdi, A. Mason, K. Najafi, and K. D.Wise, "A generic interface chip for capacitive sensors in low-power multi-parameter microsystems", Sensors and Actuators A, 84:351-361, 2000.

[9] N. Yazdi, H. Kulah, and K. Najafi, "Precision readout circuits for capacitive microaccelerometers", In Proceedings IEEE Sensors Conference, pages 28-31, 2004.

[10] Aline Baggio "Wireless sensor networks in precision agriculture"The Netherlands IEEE Pervasive Computing, 3(1):38-45, Jan-Mar 2004.

[11] P. M. Faia , C. S. Futado and A. J. Ferreira "Humidity sensing properties of a thick-film titania prepared by a slow spinning process," Sens. Actuators B, Chem., vol. 101, pp. 190, Jun. 2004.

[12] E. J. Connoly , G. M. O"Halloran , H. T. M. Pham , P. M. Sarro and P. J. French "Comparison of porous silicon, porous polysilicon and porous silicon carbide as materials for humidity sensing applications," Sens. Actuators A, Phys., vol. 99, pp. 25, Apr. 2002.

[13] A.Salehi , A. Nikfarjam and D.-J. Kalantari "Pd/porous-GaAs Schottky contact for hydrogen sensing applications,” Sens. Actuators B, Chem., vol. 113, pp. 419, Jan. 2006.

[14] B. S. Kang , S. Kim , F. Ren , B. P. Gila , C. R. Abernathy and S. J. Pearton "Comparison of MOS and Schottky W/Pt-GaN diodes for hydrogen detection," Sens. Actuators B, Chem., vol. 104, pp. 232, Jan. 2005.

[15] Pertijs, Michiel A.P., Huijsing, Johan H. "Precision Temperature Sensors in CMOS Technology", Springer, 2007.

[16] John L. Schmalzel,Fernando Figueroa,Jon Morris,Mark Turowski,"Making Smart Sensors Intelligent: Building on the IEEE 1451.x Standards", 54th International Instrumentation Symposium, Pensacola, FL USA, pp. 1-33,May 2008. 
International Journal of Wireless \& Mobile Networks (IJWMN) Vol. 3, No. 1, February 2011

[17] Y. M. Niu, Y. S. Wong and G. S. Hong "An intelligent sensor system approach for reliable tool flank wear recognition", International Journal of Advanced Manufacturing Technology, Springer London,Vol.14, No.2, pp. 77-84, February, 1998.

[18] Randy Frank, "Understanding smart sensors", Artech House sensors library, 2000.

[19] Apala Ray, "Planning and Analysis Tool for Large Scale Deployment of Wireless Sensor Network", International Journal of Next-Generation Networks (IJNGN), Vol.1, No.1, pp. 29 36, December 2009.

[20] Jon S. Wilson, “Sensor Technology Handbook”, Elsevier Inc. 2005.

[21] Dr. Shuchita Upadhayaya and Charu Gandhi, "Quality of Service Routing in Mobile Ad Hoc Networks Using Location and Energy Parameters", International Journal of Wireless \& Mobile Networks (IJWMN), Vol 1, No 2, pp. 139-147, November 2009.

[22] NI Multisim user manual ${ }^{\mathrm{TM}}$, “Analog Devices Edition: Getting Started with NI Multisim Analog Devices Edition”, available online. http://www.ni.com/pdf/manuals/372330a.pdf

[23] Ramon PallaÁs-Areny, John G. Webster, "Sensors and signal conditioning”, A WileyInterscience publication, 2000.

[24] Honeywell Datasheet ${ }^{\circledR}$, "HCH-1000 Series - Capacitive Humidity Sensor", available online, http://sensing.honeywell.com/index.cfm/ci_id/146573/la_id/1/document/1/re_id/0.

[25] Christos Efstratiou, Nigel Davies, Gerd Kortuem, Joe Finney, Rob Hooper, Mark Lowton, "Experiences of Designing and Deploying Intelligent Sensor Nodes to Monitor Hand-Arm Vibrations in the Field", Proc. of International Conference On Mobile Systems, Applications And Services, pp. 127-138,June 2007.

[26] Shinya Ito and Kenji Yoshigoe, "Performance Evaluation of Consumed energy- Type-Aware Routing (Cetar) for Wireless Sensor Networks", International Journal of Wireless \& Mobile Networks (IJWMN), Vol 1, No 2,pp. 90-101, November 2009.

[27] Peter Ashenden, Gregory Peterson, Darrell Teegarden, “The System Designer's Guide to VHDLAMS”, Elsevier Inc, 2005.

[28] Harry L. Field and John B. Solie, "Introduction to Agricultural Engineering Technology : A Problem Solving Approach”, Springer Science \& Business Media, 2007.

[29] Creed Huddleston, "Intelligent Sensor Design Using the Microchip dsPIC®” , Elsevier Inc., 2007.

[30] Hemanta Kumar Kalita and Avijit Kar, "Wireless Sensor Network Security Analysis", International Journal of Next-Generation Networks (IJNGN), Vol.1, No.1, pp. 1 - 10, December 2009.

[31] Gerard C.M. Meijer, “Smart Sensor Systems”, John Wiley \& Sons, 2008.

[32] Kazem Sohraby, Daniel Minoli, Taieb Znati, "Wireless sensor networks: technology, protocols, and applications", John Wiley \& Sons, Inc., 2007.

[33] S.C. Mukhopadhyay · G.S. Gupta, "Smart Sensors and Sensing Technology”, Springer, 2008.

[34] Twan Basten, Marc Geilen, Harmke de Groot, “Ambient Intelligence: Impact on Embedded System Design”, Kluwer Academic Publishers, 2004.

[35] W.J. Staszewski, C. Boller, G.R. Tomlinson, "Health monitoring of aerospace structures : smart sensor technologies and signal processing”, John Wiley \& Sons Inc., 2004.

[36] Jovanov E, Lords AO, Raskovic D, Cox PG, Adhami R, Andrasik F "Stress monitoring using a distributed wireless intelligent sensor system”, IEEE Eng Med Biol Mag., vol . 3, pp. 49-55, May 2003. 
International Journal of Wireless \& Mobile Networks (IJWMN) Vol. 3, No. 1, February 2011

Kshitij Shinghal has 11 Years of experience in the field of Academic and is actively involved in research \& development activities. He obtained his Masters degree (Digital Communication) in 2006 from UPTU, Lucknow. He started his career from MIT, Moradabad. Presently he is working as an Associate Professor \& Head, Deptt of E\&C Engg., at MIT Moradabad. He has published number of papers in national journals, conferences and seminars. He has guided two Masters, more than sixty students of B. Tech, and guiding three M. Tech. theses. He is an active Member of Various Professional Societies such as ISTE, IACSIT, IAENG etc.

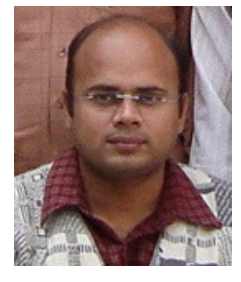

Arti Noor has 17 Years of R\&D experience in the field of VLSI design \& technology characterization, VHDL \& computer programming, and speech synthesis. She obtained her Ph.D. (Electronics and communication Engineering) in 1990 from Banaras Hindu University, Banaras. She started her career from CEERI, Pilani and then joined the CDAC, Noida as Scientist EI. Presently she is working as an Associate Professor (Scientist-E) \& HoD, M. Tech VLSI Division at CDAC Noida. She was also involved in various research development activities in CEERI, Pilani and in CDAC, Noida. She worked on many consultancy projects

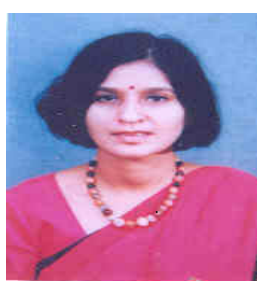
for ISRO Bangalore, IIT Delhi, ISAC Bangalore, and VSSC Trivandram. She has guided Two Ph.D in the area of Microelectronics and VLSI Design, 50 students of B.Tech/M.Sc./ M. Tech/ ME, more than 15 M.Tech. theses.

Neelam Srivastava has 22 Years of experience in the field of Wireless Sensor Network design. She obtained her Ph.D. (Electronics and communication Engineering) in 2004 from Lucknow University, Lucknow. She started her career from IET, Lucknow. Presently she is working as an Associate Professor, Deptt of E\&C Engg., at IET Lucknow. She is involved in various research \& development activities. She is guiding two Ph.D. in the area of Wireless Sensor Networks, 50 students of B. Tech, more than $15 \mathrm{M}$. Tech. theses.

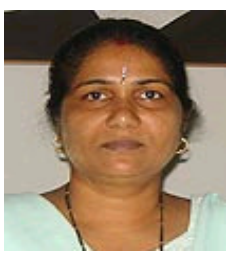

Raghuvir Singh has experience in Research, Development, Teaching and Administration for more than 40 years. He obtained his B.Sc., B.E. (Telecommunication), M.E. (Electronics) and Ph.D. (Electronics and communication Engineering) Degrees in 1958, 1962 \& 1970 respectively. He worked in CEERI, Pilani and retired as Head of Electronics \& Communication Engineering Department of University of Roorkee (presently IIT Roorkee). He was awarded the IETE award in 1965, Khosla Research Award in 1970 and Anna University National Award for his outstanding career and contribution to

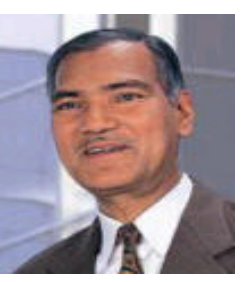
Engineering and Technology in 1994.His name was recommended by IETE Award Committee for the FICCI Award in 1999. He has supervised 5 Ph.D. theses, 45 M.E. dissertations and has more than 50 publications in National and International Journals and conferences to his credit. 